\title{
Interfaces entre escolas do campo e movimentos sociais no Brasil
}

\author{
Ramofly Bicalho Santos ${ }^{1}$ \\ ${ }^{1}$ Universidade Federal Rural do Rio de Janeiro - UFRRJ, Departamento de Educação do Campo, Movimentos \\ Sociais e Diversidade. Instituto de Educação. Campus Seropédica. BR-465, Km 7, Seropédica, Rio de Janeiro. \\ Brasil.ramofly@gmail.com.
}

\begin{abstract}
RESUMO. O presente artigo tem como objetivo central apresentar reflexões acerca da produção crítica do conhecimento, atrelada aos princípios da educação do campo e dos valores contra hegemônicos defendidos pelos movimentos sociais. Neste trabalho, realizamos uma sucinta abordagem, indicando os principais problemas enfrentados no fechamento das escolas do campo. Desenvolvemos uma pesquisa bibliográfica e documental, utilizando fontes de investigação, legislações, portarias, decretos e referenciais teóricos produzidos sobre tal temática no Brasil. Concluímos que a produção coletiva do saber, em parceria com educandos, educadores, comunidades e movimentos sociais de luta pela terra, pode dialogar com histórias, memórias, identidades, desejos, valores e reconhecimento, fortalecendo os debates em torno da educação do campo, na estreita relação com as universidades públicas, escolas, secretarias municipais e estaduais de educação. Constatamos que tal articulação é um dos principais desafios a ser enfrentado pelos sujeitos, individuais e coletivos. A escola, nesse sentido, pode proporcionar reflexões que eduque e contribua para apontar caminhos de uma realidade mais humana para as diversas populações camponesas.
\end{abstract}

Palavras-chave: Escolas do campo, Movimentos Sociais, Educação do Campo. 


\title{
Interfaces field schools and social movements in Brazil
}

\begin{abstract}
This article has as main objective to present reflections on the critical production of knowledge, linked to the principles of the field of education and values against hegemonic defended by social movements. We carried out a succinct approach, indicating the main problems facing the closure of schools in the field. Developed a bibliographical and documentary research, using sources of research, laws, ordinances, decrees and theoretical frameworks produced on this theme in Brazil. We conclude that the collective production of knowledge, in partnership with students, educators, communities and social movements struggling for land, can dialogue with stories, memories, identities, desires, values and recognition, strengthening the debates around the field education, close relationship with public universities, schools, municipal and state education. We note that this joint is one of the main challenges to be faced by the subjects, individual and collective. The school, in this sense, can provide reflections that educates and helps to point out ways of a more human reality for many rural populations.
\end{abstract}

Keywords: Schools Field, Social Movements, Education Field. 


\section{Escuelas de campo $y$ interfaces movimientos sociales en Brasil}

RESUMEN. Este artículo tiene como principal objetivo presentar reflexiones sobre la producción crítica de conocimiento, vinculada a los principios de la esfera de la educación y los valores contra hegemónica defendidos por los movimientos sociales. Hemos llevado a cabo una aproximación sucinta, con indicación de los principales problemas que enfrenta el cierre de escuelas en el campo. Desarrollado una investigación bibliográfica y documental, el uso de fuentes de investigación, leyes, ordenanzas, decretos y marcos teóricos producidos sobre este tema en Brasil. Llegamos a la conclusión de que la producción colectiva de conocimiento, en asociación con los estudiantes, educadores, comunidades y movimientos sociales que luchan por la tierra, puede dialogar con historias, memorias, identidades, deseos, valores y el reconocimiento, el fortalecimiento de los debates en torno al campo de la educación, estrecha relación con las universidades públicas, las escuelas, la educación municipal y estatal. Observamos que esta articulación es uno de los principales retos que hay que afrontar por los sujetos, individuales y colectivos. La escuela, en este sentido, puede proporcionar reflexiones que educa y ayuda a señalar las formas de una realidad más humana para muchas poblaciones rurales.

Palabras clave: Campo de Escuelas, Movimientos Sociales, Campo de la Educación. 


\section{Introdução}

Nossa intenção com este artigo é apresentar algumas posições acerca da educação do campo, numa estreita relação com os movimentos sociais. Compreender ainda os debates que incorporam processos de ensino-aprendizagens nas escolas do campo, ora de maneira muito superficial e contraditória, utilizando as categorias: educação rural, educação no campo e ensino tradicional. Em outras ocasiões, mais articuladas às seguintes políticas públicas: Diretrizes Operacionais por uma Educação do Campo ${ }^{i}$, PROCAMPO Programa de Apoio à Formação Superior em Licenciatura em Educação do Campo ${ }^{\mathrm{ii}}$, Decreto Presidencial $\mathrm{n}^{\mathrm{o}} 7.352^{\mathrm{iii}}$ e $\mathrm{o}$ PRONACAMPO - Programa Nacional de Educação do Campo ${ }^{\text {iv }}$. Nesse sentido, nosso objetivo é compreender as escolas do campo atreladas aos fatores culturais, políticos e sociais que influenciam as diferentes etapas e processos históricos de produção dos saberes. Entendemos que a formação docente e as transformações atuais da educação do campo, podem ser vistas como possibilidades de expressão da gestão democrática e emancipatória.

Este texto é parte das reflexões e pesquisas realizadas, nos últimos anos, acerca das possíveis relações entre os processos de ensino-aprendizagens nas escolas do campo vinculadas aos movimentos sociais, em especial, o MST Movimento dos Trabalhadores Rurais Sem Terra, na busca por direitos humanos e respeito às diferenças sociais, culturais e religiosas. Uma das nossas preocupações foi conhecer os princípios políticos e pedagógicos da educação do campo, suas bandeiras de lutas e projetos emancipadores, considerando os seguintes desafios: formação política dos sujeitos, trabalho coletivo, valorização das histórias de vida, consciência social, educação popular e saberes históricos de educadores, educandos e lideranças dos movimentos sociais $^{\mathrm{v}}$. (Gohn, 2002).

A educação do campo na sua estratégica relação com os movimentos sociais pode contribuir no fortalecimento das escolas, reconstruindo passados, memórias, identidades e histórias de vida de educadores e educandos. Estes sujeitos poderão se envolver com as questões político-pedagógicas apresentadas pelos movimentos sociais, numa construção coletiva que considere as inúmeras possibilidades do fazer democrático e crítico. Segundo (Bogo, 2000, p. 31): “a transformação da sociedade se assemelha à construção de um prédio, não basta ter uma planta bem feita na mão, é preciso que lá 
nas minas haja operários extraindo cimento, outros transportando, outros cavando e transportando areia (...)”.

Nesta investigação utilizamos, predominantemente, a pesquisa bibliográfica e documental, considerando o universo das crenças, valores, atitudes, motivações e histórias dos sujeitos, individuais e coletivos, presente nas escolas. Ela permitiu explorar a diversidade de materiais bibliográficos vinculados ao MST, em especial, o Caderno de Educação n ${ }^{\circ} 8$ - Princípios da Educação no MST, além de legislações ${ }^{\mathrm{vi}}$, decretos e portarias que tratam das políticas públicas de educação do campo no Brasil, formação docente, projetos político-pedagógicos emancipadores, agricultura familiar, orgânica e agroecológica. As minhas atividades na Coordenação e Docência da Licenciatura em Educação do Campo vii e do Programa Escola Ativa ${ }^{\text {viii }}$, ambos na UFRRJ Universidade Federal Rural do Rio de Janeiro, permitiu uma inserção social mais profunda na realidade, explorando a diversidade de espaços, documentos e referências bibliográficas vinculadas aos movimentos sociais.

Com tal metodologia, aprofundamos a compreensão da realidade, respeitando as experiências pessoais e sociais dos indivíduos e seus coletivos, predominantemente, nas escolas municipais do campo no Rio de Janeiro. Nossa preocupação com a realidade não foi quantificá-la, visto que exploramos um universo de significações, conhecimentos, identidades, memórias, experiências e histórias de vida bem diversificadas, contribuindo para formação de novos sujeitos sociais, numa perspectiva popular e histórica. Acreditamos nessa dimensão educativa e no fazer pedagógico que tais sujeitos realizam através da organização coletiva. Importante ressaltar que a observação foi uma das técnicas utilizadas, em especial, por se tratar de estudos na área de ciências humanas e sociais. Embora seja uma técnica relativamente espontânea, a observação exige considerável sistematização de método, que a potencializa.

\section{Escolas do campo e movimentos sociais}

Partimos do princípio que a mística, a luta pela liberdade, a utopia, a solidariedade e os trabalhos coletivos são valores essenciais na consolidação das escolas do campo atreladas aos movimentos sociais. Soma-se ainda, a luta por reforma agrária, por projetos políticos pedagógicos emancipadores que contribuam na formação de educadores e educandos, a defesa se uma alimentação saudável, considerando a agricultura 
familiar, orgânica e agroecológica. Nessa conjuntura, é essencial o envolvimento das secretarias estaduais e municipais no debate sobre os princípios da educação do campo. Devem considerar na organização curricular, por exemplo, as emoções presentes nas cantorias, nas músicas, poesias, literaturas e histórias de vida dos sujeitos camponeses. Importante ainda articular as diversas atividades acadêmicas e profissionais realizadas por educadores e educandos nas escolas do campo. Para os movimentos sociais, as místicas e encenações, os abraços, bonés e bandeiras podem colaborar com as noções de cidadania e consciência emancipadora, através de atos públicos e ocupações dos latifúndios improdutivos. (Benjamin \& Caldart, 2000; Antunes \& Martins, 2012; Caldart, 2010).

Com os princípios da educação do campo são apresentadas as possibilidades de lutas e construção de uma sociedade mais justa, solidária e cidadã. Que valorize os sonhos e as utopias dos trabalhadores camponeses e seus movimentos sociais, numa defesa constante por educação emancipadora. Tais princípios alimentam a esperança de lideranças e militantes quilombolas, indígenas, caiçaras, acampados e assentados da reforma agrária. Mobiliza homens e mulheres no enfrentamento das dificuldades e na luta pelo reconhecimento das identidades vinculadas a terra. Reafirmamos que as místicas, os sonhos, as poesias e lutas revigoram os sujeitos, individuais e coletivos, da educação do campo. Tais valores elevam o entusiasmo e contribuem no enfrentamento dos fracassos e desajustes de um país com altíssima concentração de renda e terra. No processo de consolidação das lutas por emancipação, cultura e diversidade, é essencial a estreita articulação entre escolas do campo, movimentos sociais e mística. (Souza, 2010, 2011; Vendramini, 2009, 2000).

Nesta conjuntura, são incentivadas as relações entre os domínios teóricos, práticos, intelectuais e da cultura popular. Vive-se a esperança, a dignidade e os valores de um mundo melhor para crianças, jovens, adultos, homens e mulheres, independente, entre outros aspectos, de credo religioso, faixa etária, etnia e gênero. Busca-se a emancipação dos indivíduos, valorização do trabalho coletivo e fortalecimento da sociedade civil organizada. (Stédile, 1999, p. 130) afirma que: "os exemplos de sacrifícios são enormes. As famílias permanecem tanto tempo acampadas porque têm a mística e os princípios organizativos, não é só porque a terra é necessária”. 
As músicas e cantorias utilizadas por agricultores familiares, educadores e educandos nas escolas do campo, são extremamente significativas na valorização e reconhecimento dos espaços de ensinoaprendizagens. Serve como renovação dos sonhos, utopias, ideais e valores da dignidade humana. Reconhecer as realidades camponesas, suas festas, confraternizações, piadas, memórias, enfrentamentos com autoridades policiais e marchas na luta pela terra, são atitudes valorizadas pelos sujeitos da reforma agrária e pela educação do campo, numa perspectiva emancipadora, em diálogo com as místicas, lembranças dos antigos companheiros e renovação das forças nos momentos de incertezas.

Tais valores podem contribuir para enfrentar, entre outras questões, o latifúndio improdutivo, a miséria no campo, a utilização dos agrotóxicos, as sementes transgênicas e o irresponsável fechamento das escolas do campo no Brasil. Mostram ainda, o desrespeito acerca da desvalorização dos saberes e histórias de vida dos sujeitos. Nessa conjuntura de opressão, os movimentos sociais intensificam a formação política com suas lideranças, contribuindo na consolidação de espaços emancipadores com intensa atuação de educadores, educandos, trabalhadores do campo e da cidade. (Molina, 2014; Souza, 2012).

Outro aspecto extremamente relevante no diálogo com as escolas são as licenciaturas em educação do campo, oferecidas por várias universidades públicas brasileiras. Nesses espaços, presenciamos inúmeros debates, conflitos de ideias e reconstrução de valores. Mecanismos que fazem emergir sonhos e esperanças de educadores, educandos, movimentos sociais e trabalhadores rurais, num projeto coerente com a realidade de vida desses sujeitos. É estratégica a valorização de tais escolas como espaços de construção da cidadania plena, contrária às ações reprodutivistas e produtoras das desigualdades sociais, diretamente envolvida com as lutas por inclusão social, defesa dos direitos humanos, soberania alimentar, agricultura familiar, agroecológica e orgânica. Deve ainda combater e denunciar a utilização dos agrotóxicos, transgênicos, assassinatos de lideranças, criminalização dos movimentos sociais e a histórica presença dos latifúndios improdutivos. Uma escola do campo que busque a igualdade e o direito a terra. Que saiba lidar, entre outras questões, com as diferenças de gênero, étnica, social e de geração, num projeto político pedagógico que contribua para emancipação de educadores e educandos, 
valorizando a produção escrita e oral. (Caldart; Stédile \& Daros, 2015; Caldart; Pereira; Alentejano \& Frigotto, 2012).

Nos processos de formação e experiências educativas reais, os movimentos sociais lutam por escolas que protagonizem histórias, individuais e coletivas, problematizando-as. A luta por uma educação do campo passa pelo enfrentamento das várias cercas impostas pela escola tradicional, com seus projetos autoritários e deslocados da realidade camponesa. Essas cercas quando derrubadas simbolizam respeito, organização e valorização dos movimentos sociais. Faz a sociedade refletir acerca das dificuldades encontradas em nosso país, em especial, a miséria, o latifúndio e o analfabetismo. Esses são espaços de aprendizagens coletivas, construção política e luta pelo reconhecimento identitário. (Honneth, 2003).

Importante ressaltar a contribuição das diretrizes nacionais por uma educação do campo, marco nos debates sobre as políticas públicas em educação do campo, defendidas pelos diversos movimentos sociais na formação política e pedagógica de pescadores, ribeirinhos, quilombolas, acampados e assentados da reforma agrária, caiçaras, entre outros sujeitos históricos e sociais envolvidos com a luta pela terra, as memórias e identidades presentes nas escolas do campo. Entendemos que as histórias de vida de educadores e educandos poderão contribuir para ressignificar as relações sociais, a construção coletiva e emancipadora do conhecimento, como espaços alternativos de produção crítica dos saberes.

Historicamente, a escola do meio rural, atrelada ao tradicionalismo, não reconheceu o potencial de educadores e educandos, suas histórias de vida, valores e sonhos. Diversas oportunidades foram perdidas na construção dessa identidade do campo. (Honneth, 2003) sinaliza que o desrespeito à identidade pode acarretar maus-tratos práticos. Esse desrespeito retira do ser humano todas as possibilidades da livre disposição sobre o seu corpo. Representa a espécie mais elementar de rebaixamento pessoal e pode provocar a baixa-estima dos sujeitos, afetando, inclusive, as diversas atividades coletivas. Nessa conjuntura, os valores e os saberes da terra se distanciam da realidade de vida de educadores e educandos, dos livros didáticos, dos conteúdos históricos e das metodologias. Com a intensificação das contradições internas, o reconhecimento identitário é recusado. (Honneth, 2003) destaca que o processo de construção e fortalecimento da identidade pessoal e coletiva dos sujeitos passa, 
necessariamente, pela luta por reconhecimento.

Nas diretrizes nacionais por uma educação do campo, os conceitos de identidade, histórias de vida e memória são essenciais. (Caldart, 2004) afirma a necessidade de assumir o conceito de identidade com orgulho, enfrentando os desafios presentes. A educação como prática da liberdade (Freire, 1983) pode contribuir na formação de sujeitos que respeitem tais valores e os diversos aspectos, históricos e culturais, que dele fazem parte. A educação do campo, e nela, a educação libertadora, os debates acerca da reforma agrária e a formação política de educadores, educandos e lideranças dos movimentos sociais, defende, entre outros aspectos, as inúmeras possibilidades de transformação nas relações de poder, na valorização da produção agroecológica e orgânica, além de denunciar a utilização de agrotóxicos, pesticidas e vermicidas. $\mathrm{O}$ educador/a do campo deve se apropriar desses debates, respeitando, por exemplo, as diferentes posturas acerca das relações de gênero, em ambientes solidários, essenciais na construção de uma sociedade mais justa para todos. Para (Stédile, 1999, p. 107)

Não estamos somente preocupados com a conquista de um pedaço de terra, mas com a formação integral de toda nossa base social. Queremos ser libertos e construir comunidades bonitas, com outras relações sociais, baseadas na amizade, na solidariedade. Enfim, comunidades desenvolvidas, no sentido pleno da palavra.

$\mathrm{Na}$ educação do campo, a formação integral dos sujeitos deve considerar os aspectos políticopedagógicos, na sua estreita relação com as atividades coletivas desempenhadas nas lavouras, na criação dos animais, nas marchas e escolas do campo. Não se constrói, absolutamente nada de autônomo e emancipador, se os sujeitos, individuais e coletivos, estão distantes das questões identitárias e históricas que tocam o fazer pedagógico. A organização coletiva de educadores e educandos é estratégica na superação dos desafios.

Importante salientar nossa preocupação com as diversas possibilidades de envolvimento geradas pelo coletivo. Este não é libertador, quando as atitudes tomadas passam pelo receio de ser diferente e contrária a maioria do grupo. Assim, nesse processo de organização e envolvimento coletivo, (Abramovay, 1985, p. 57) argumenta que: "os acampados, ao se organizarem coletivamente, deixam de ser apenas os objetos do processo de reforma agrária e tornam-se sujeitos, eles passam do plano receptivo para o ativo". Nesse sentido, a luta por educação do campo, incorpora a 
ocupação, enquanto estratégia utilizada pelos movimentos sociais. Luta popular de resistência coletiva, em defesa dos ideais de aprendizagens e emancipação política. O coletivo, nessa conjuntura, pode ser libertador, desde que a valorização das escolas e a formação crítica de educadores e educandos, sejam acompanhadas de resistências múltiplas.

Compreendemos que as ocupações dos latifúndios improdutivos, os debates travados pelos movimentos sociais com as secretarias municipais e estaduais de educação e as universidades públicas, fortalecem as ações da educação do campo. Os acampamentos, nessa conjuntura, são espaços de luta pelo reconhecimento. Nele, presenciamos diferentes formas de resistir ao intenso calor, o frio exagerado, as diversas doenças, a fome, a miséria, a falta de água corrente e potável e longos períodos com pouquíssima iluminação, sob a lona preta. Dificuldades presentes, inclusive, nas diversas escolas do campo multisseriadas. Por outro lado, (Abramovay, 1985) afirma que acampar consiste em tomar a ofensiva da luta. Demonstra que os agricultores são capazes de transformarem-se em agentes da construção de sua própria identidade política. Essas experiências ressaltam a organização dos camponeses na luta pela terra e dos educadores na luta por escolas do campo. São maneiras diferenciadas de resistir coletivamente, valorizando suas histórias de vida e envolvendo os sujeitos em projetos político-pedagógicos emancipadores.

A educação do campo, nessa perspectiva, surge como atividade coletiva e de ação que envolve expectativas, compromissos e mostra a realidade de injustiças contra o homem e a mulher do campo. Estes sujeitos desafiam o estado, representante legítimo dos interesses da burguesia. As marchas, coletivamente organizadas, podem servir como ferramentas de formação e pressão política, com atos públicos, envolvendo educadores, educandos, crianças e idosos na divulgação da luta pela terra e educação. Visitam-se igrejas, sindicatos, escolas e associações de moradores. As palestras, vídeos e caminhadas atuam na divulgação dos valores e princípios dos movimentos sociais. Impossível à escola do campo não dialogar com tais experiências. Ela pode contribuir com educadores, educandos, acampados, assentados e demais integrantes dos movimentos sociais no adeus à inocência. A poesia de Pedro Tierra: somos a perigosa memória das lutas, no livro de (Fernandes, 1999, p. 153), afirma:

Quando um homem, uma mulher, um grupo de homens e mulheres, 
milhares de homens e mulheres e crianças naquelas horas de sombra indefiníveis, quando já não distinguirmos se ainda é noite, se já é madrugada, concentram toda a força dos excluídos em suas mãos, toda a força desse primitivo impulso de justiça que nos alimenta o coração, toda a força do sonho em suas mãos, toda força de sua classe em suas mãos, o alicate morde o fio e o arame estala como a corda de um violino e a cerca vem abaixo: eles dão adeus à inocência.

Nessa intensa e estreita relação entre as ocupações de terras organizadas pelos movimentos sociais e os diversos saberes e fazeres da escola compreendemos que os gestos, os sonhos, as identidades, as memórias, as narrativas e os sentimentos ocupam espaços fundamentais na construção e consolidação de projetos político-pedagógicos emancipadores. (De Rossi, 2004; Veiga, 2004). Esses espaços alternativos de produção dos saberes da terra devem considerar os anseios das escolas do campo, e nela, os educadores, educandos, movimentos sociais e demais integrantes da comunidade. Compreender o cotidiano da escola é sempre uma opção política de bastante coragem histórica. Requer preparação, disciplina, maturidade, dedicação, esperança, utopia e organização no enfrentamento das seguintes adversidades: fome, pobreza, medos, insegurança e desgaste emocional. Os movimentos sociais através de suas lideranças, coletivos, coordenações e brigadas exercem papéis extremamente relevantes no enfrentamento dessas dificuldades, criando-se estratégias para lidar com as dúvidas e inquietações dos sujeitos, em torno dos seus projetos de vida e sociedade. Tais questões são geralmente trabalhadas na organização das místicas, das marchas, nos encontros estaduais e nacionais e em reuniões nas escolas do campo.

Nessa conjuntura, é essencial o envolvimento crítico de educadores, educandos, gestão das escolas, secretarias municipais e estaduais de educação, além da intensa participação dos movimentos sociais. As tomadas de decisões devem, necessariamente, zelar pela ética e transparência. As escolas do campo não podem desconsiderar a realidade dos sujeitos, individuais e coletivos. Dependendo do grau de organização, conscientização e coerência acerca dos valores defendidos por tais atores, a implementação dos princípios da educação do campo, enquanto política pública, pode conviver com avanços ou retrocessos.

Os coletivos de educação do campo representados pelos movimentos sociais, pelas universidades e licenciaturas em educação do campo, vem denunciando o desrespeito de algumas secretarias municipais e estaduais de educação, no deslocamento dos professores para as 
escolas do campo. Essa é uma maneira de punir o educador, gerando preconceitos, desavenças e desrespeito aos saberes e as identidades dos sujeitos camponeses. O PRONERA - Programa Nacional de Educação na Reforma, as Diretrizes Operacionais por uma Educação do Campo, o PROCAMPO - Programa de Apoio à Formação Superior em Licenciatura em Educação do Campo, o Decreto $\mathrm{n}^{\mathrm{o}} 7.352$, de 4 de novembro de 2010 e o PRONACAMPO - Programa Nacional de Educação do Campo, podem ser encarados como políticas públicas de formação política e identitária dos sujeitos que rompem com essa lógica punitiva dos educadores/as. Entendemos que os debates em torno da educação do campo potencializam as experiências, lutas e resistências dos movimentos sociais na luta por mais escolas do campo, livros didáticos, formação de educadores, merenda escolar, bibliotecas, estradas transitáveis, laboratórios e quadras poliesportivas. (Hage, 2011).

O Decreto $\mathrm{n}^{\circ} 7352 / 10$, vinculado ao PRONERA, afirma em seu artigo $1^{\circ}$, que a política de educação do campo, destina-se à ampliação e qualificação da oferta de educação básica e superior às populações do campo e será desenvolvida pela União, em regime de colaboração com Estados, Distrito Federal e Municípios, de acordo com as diretrizes e metas estabelecidas no Plano Nacional de Educação. Para os efeitos deste Decreto, entende-se por: I populações do campo: agricultores familiares, extrativistas, pescadores artesanais, ribeirinhos, assentados e acampados da reforma agrária, trabalhadores assalariados rurais, quilombolas, caiçaras, povos da floresta, caboclos e outros que produzam suas condições materiais de existência, a partir do trabalho no meio rural. II - escola do campo: aquela situada em área rural, conforme definida pelo Instituto Brasileiro de Geografia e Estatística - IBGE ou aquela situada em área urbana, desde que atenda, predominantemente, populações do campo.

Serão consideradas do campo as turmas anexas vinculadas às escolas com sede em área urbana, devendo elaborar seu projeto político pedagógico, na forma estabelecida pelo Conselho Nacional de Educação. Reiteramos que a educação do campo concretizar-se-á mediante a oferta de formação inicial e continuada de profissionais da educação, garantia de condições de infraestrutura e transporte escolar, bem como, materiais e livros didáticos, equipamentos, laboratórios, bibliotecas, áreas de lazer e desporto, adequados ao projeto político pedagógico e, em conformidade, com a realidade local 
e diversidade das populações do campo. (Oliveira, 2015, p. 50).

Importante ainda citar a Resolução $\mathrm{n}^{\circ}$ 04 de Julho de 2010. Ela reforça a relação político-cultural entre movimentos sociais do campo e organicidade pedagógica. A aludida base legal recomenda que o processo de escolarização tenha a seguinte orientação: a identidade da escola do campo é definida pela vinculação com as questões inerentes à sua realidade, com propostas pedagógicas que contemplem sua diversidade em todos os aspectos sociais, culturais, políticos, econômicos, de gênero, geração e etnia. As formas de organização e metodologias pertinentes à realidade do campo devem ser acolhidas, em especial, a pedagogia da terra, quando se busca desenvolver trabalhos fundamentados no princípio da sustentabilidade, para assegurar a preservação das futuras gerações. (Oliveira, 2015, p. 48).

Entendemos que a educação do campo pode contribuir na elevação da autoestima, da autonomia e na formação crítica do ser humano. Tais atitudes não estão desvinculadas da capacidade de mobilização dos acampados, assentados, ribeirinhos, quilombolas, pescadores, caiçaras, entre outros sujeitos, individuais e coletivos. A educação do campo é uma conquista dos movimentos sociais, fortalecida nos embates, na participação, nas experiências e cooperação. Através das lutas políticas, essenciais para educadores, educandos e movimentos sociais, rompe-se com o tradicional isolamento e individualismo imposto pela sociedade neoliberal. Nessa conjuntura, os espaços de reconhecimento e resistência são criados e recriados, com participação efetiva dos sujeitos. (Caldart, 2012, p. 261) apresenta um conjunto de questões no processo em curso da educação do campo:

Como defender a educação dos
camponeses sem confrontar a lógica
da agricultura capitalista que prevê
sua eliminação social e mesmo
física? Como pensar em políticas de
educação no campo ao mesmo tempo
em que se projeta um campo com
cada vez menos gente? Como admitir
como sujeitos propositores de
políticas públicas, movimentos
sociais criminalizados pelo mesmo
Estado que deve instituir essas
políticas? A educação do campo para (Caldart, 2012, p. 262) está além da educação escolar: "uma política de educação do campo nunca será somente de educação em si mesma e nem de educação escolar, embora se organize em torno dela." (Campos, 2015, p. 88) apresenta os seguintes questionamentos: como experiências de educação não escolar (experiências produzidas pelos movimentos sociais) podem ser circunscritas/restritas ao espaço escolar? O 
que se perde na transformação da escola comunitária, construída na luta coletiva, em escola do Estado? Que saberes e práticas da comunidade são expulsos? Como educação não escolar, por que o movimento social organiza suas lutas "em torno da escola", em torno de demandas por políticas públicas? O que se perde e se ganha com isso?

As atuais experiências de luta por educação do campo exigem a consolidação das escolas do campo, e nela, a ciranda infantil, o ensino fundamental do $1^{\circ}$ ao $9^{\circ}$ ano, a alfabetização e educação de jovens e adultos, além de educadores/as formados nas licenciaturas em educação do campo. Nesse contexto é fundamental ressignificar olhares, lugares, trajetórias, protagonismos, histórias, memórias e identidades camponesas, em prol das políticas públicas de educação do campo, na sua estreita relação com os movimentos sociais. Para (Caldart, 2000, p. 04): “Cada sem-terra que entra no MST entra também num mundo já produzido de símbolos, gestos, exemplos humanos, valores, que a cada ação ele vai aprendendo a significar e ressignificar”.

Tais comportamentos contribuem para enaltecer as relações de solidariedade entre os sujeitos, alicerçadas nas histórias de vida, sonhos e utopias. A luta por educação do campo alimenta a esperança de educadores, educandos e movimentos sociais. Frente os fracassos impostos, numa conjuntura altamente conservadora e autoritária, homens e mulheres enfrentam, com criticidade, resistências e entusiasmos, as dificuldades e desajustes da sociedade brasileira. Num estreito diálogo com as místicas, poesias, sonhos e utopias, lutam e vivem a vida, com dignidade. (Stédile in Bogo, 2002, p. 08), afirma que:

No MST, a poesia é mais do que uma
simples arte. É a forma de animar os
passos na busca da terra que se
distanciou dos corpos de quem
precisa dela para marcar o tempo de
sua existência. (...) esta pedagogia de
dizer com versos está enraizada na
existência de poetas e poetizas que
nos antecederam e vivem em seus
versos, emendados nos versos de
nossos jovens e crianças que, sob as
lonas pretas, não deixam de sonhar
com a liberdade. A política sem
poesia perde a consciência das
mudanças que deve alcançar.
Perdendo a consciência, perde os
sentimentos. Sem sentimentos o
homem vira pedra; elas não falam de
si, apenas fazem a terra suportar seu
peso.

Sonhar, lutar, amar e respeitar são valores constantemente defendidos pelos movimentos sociais do campo. Na luta por reconhecimento identitário (Honneth, 2003), a valorização dos sujeitos é permeada por confiança, emoções, carências, esperanças e utopias, poesias, artes, versos e liberdade de pensamento. $\mathrm{O}$ reconhecimento da realidade pode renovar sonhos, ideais de coletividade e valores da 
dignidade humana. Nessa conjuntura, as escolas do campo incorporam, como parte dos conteúdos curriculares, as seguintes ferramentas pedagógicas: músicas, místicas, festas, confraternizações e piadas. Trabalha-se com memórias, narrativas, contos e lembranças dos companheiros. Tais aspectos são essenciais na renovação das forças e estímulo nos momentos de incertezas. Segundo o (MST, 2000, p. 19):

\begin{abstract}
A música, o teatro, a dança, a pintura, poesia, as festas populares - que celebram os momentos de conquista e vitória, contribuem para desenvolver a criatividade $\mathrm{e}$ habilidade artística e fortalece nossa identidade histórica e cultural. É através de momentos de arte e beleza que cultivamos novos sentidos para a caminhada e preservamos nossa história.
\end{abstract}

As escolas do campo na estreita relação com os sonhos, emoções e respeito por homens, mulheres, educadores e educandos, são encaradas como possibilidades de superação das dificuldades de formação enfrentadas pelos movimentos sociais. Dependendo do grau de envolvimento, criticidade e conscientização dos sujeitos, individuais e coletivos, os princípios da educação do campo podem gerar alívio, tensão, respeito, solidariedade e trabalho coletivo entre as pessoas. São denunciados os obstáculos apresentados nas ocupações de terras, nos acampamentos de lona preta, nas marchas intermináveis, no fechamento das escolas do campo, na utilização dos agrotóxicos, das sementes transgênicas e a criminalização dos movimentos sociais. Para (Caldart, 2000, p. 134): "O que manteve estas pessoas em Marcha, tomando chuva, fazendo bolhas no pé, exaurindo sua força física, mesmo sabendo que ainda não era para sua terra que caminhavam?"

Compreendemos que a consolidação e expansão das escolas do campo para atender, sobretudo, as demandas de escolarização básica e superior, carecem de respeito às leis nacionais e internacionais de direitos humanos, sociais e civis pelas instituições públicas. Um exemplo do descaso com as populações camponesas é a dura realidade de fechamento das escolas rurais. Entre 2003 e 2013 mais de 31,4\% dessas escolas foram fechadas, em função da nucleação, fenômeno muito presente nas secretarias municipais e estaduais de educação no Brasil. A nucleação significa a junção de duas, três ou mais escolas rurais, numa escola do núcleo urbano, denominada escola-polo. Tais espaços possuem um número maior de carteiras para atender os estudantes, na jornada de rodar quilômetros em transportes coletivos escolares, quase sempre em condições indignas $^{\mathrm{ix}}$. A questão é tão grave que, em 
28 de março de 2014, a Agência Brasil publica matéria sobre a Lei $\mathrm{n}^{\circ} 12.960$, de 27 de março de 2014, que dificulta o fechamento das escolas rurais, indígenas e quilombolas. Esta lei altera a LDB/1996 e concede aos Conselhos Municipais de Educação, manifestação sobre o assunto. ${ }^{\mathrm{x}}$ (Oliveira, 2015, p. 51).

De todos os aspectos debatidos pelos movimentos sociais na educação do campo, o mais contraditório é a política de fechamento das escolas, por parte dos sistemas estaduais e municipais de ensino, através da nucleação e oferta de transporte para deslocamento dos educandos. Esta política é reiteradamente criticada e condenada pelo MEC, pelo Conselho Nacional dos Secretários de Educação (CONSED), pela União Nacional dos Dirigentes Municipais de Educação (UNDIME) e pelo Conselho Nacional de Educação (CNE), visto que infringe, inclusive, a LDB/1996, contribui para evasão, repetência e distorção série-idade, além de afastar crianças, jovens e adultos de suas comunidades. (Oliveira, 2015, p. $55)$.

Cabe aqui informar que as políticas de educação do campo se articulam, entre outros, com o Programa Nacional de Agricultura Familiar - PRONAF, Política Nacional de Agroecologia e Produção Orgânica - PNAPO, Programa de
Aquisição de Alimentos - PAA e Programa Nacional de Alimentação Escolar - PNAE. (Campos, 2015). Nesta intensa articulação são valorizados projetos político-pedagógicos emancipadores que contemplem diversidades, identidades e sujeitos, individuais e coletivos, dos campos e das cidades. Para (Honneth, 2003), é importante perceber os conflitos que se originam das inúmeras experiências de desrespeito e de não-reconhecimento da identidade pessoal e coletiva, na esfera emotiva, social e jurídica.

Diante das dificuldades apresentadas, a luta pela sobrevivência, individual e coletiva, rompe com as várias cercas do judiciário, policial e midiática. Rompe ainda com a educação rural, tradicional e conservadora. Essas cercas quando derrubadas simbolizam respeito e valorização dos trabalhadores camponeses. Faz a sociedade refletir sobre as inúmeras desigualdades no campo brasileiro, a interminável miséria, o analfabetismo crescente e a defesa da agricultura familiar, orgânica e agroecológica. Nessa conjuntura, (Caldart, 2004) defende uma pedagogia do oprimido que se articule, nacionalmente, com a educação do campo, com os trabalhadores rurais e seus movimentos sociais. Uma educação emancipadora, histórica e identitária, que 
valorize as lutas sociais e a formação política de educadores e educandos.

\section{Considerações finais}

A conquista da educação do campo pelos movimentos sociais é um projeto em disputa pela hegemonia. Inscreve-se como um dos componentes indispensáveis das forças políticas em luta pelo alargamento da democracia na sociedade brasileira. As formas de pressão, negociação, mecanismos de decisão e permanentes tensões nas relações entre os sujeitos, individuais e coletivos, podem contribuir para consolidar a consciência crítica, a autonomia intelectual, a conquista de direitos e a coerência na utilização dos saberes da terra. As escolas do campo devem ser conquistadas, dentre outros, por educadores, educandos, movimentos sociais, agricultores familiares e demais trabalhadores/as do campo. Nessa conjuntura, percebemos avanços e recuos na implementação dos princípios da educação do campo, atrelada aos movimentos sociais e à luta pela terra, além das noções de cidadania, formação política, histórias de vida, memórias e identidades. Quero salientar que a relação entre as escolas do campo e os movimentos sociais, a produção do conhecimento e os dados coletados não são isentas de valores.
A construção crítica e coerente do saber não é neutra.

Nessa pesquisa, os princípios pedagógicos que orientam a educação do campo, consideram os contextos históricos dos movimentos sociais, suas realidades, diversidade econômica, social e cultural. Obviamente que as escolas do campo não são homogêneas para pescadores, ribeirinhos, caiçaras, atingidos por barragens, pequenos agricultores, acampados e assentados da reforma agrária, aldeias indígenas, territórios quilombolas, entre outros sujeitos / povos do campo. Nesses espaços, educadores, educandos, militantes, crianças, jovens e adultos aprendem, ensinam e se conhecem. Educa-se para cidadania e conscientização dos problemas. As dificuldades podem ser enfrentadas com perseverança, dedicação, lutas, formação continuada de educadores e políticas públicas efetivas de educação do campo. Quando ação e reflexão são organizadas com o objetivo de transformar a realidade dos sujeitos camponeses, a práxis libertadora é uma possibilidade. Nessas alianças, a educação do campo pode ser uma das ferramentas no processo de compreensão das lutas e demandas educacionais defendidas pelos movimentos sociais do campo, em especial, o combate ao fechamento de escolas. 
Assim, a história pessoal do autor permeou todo o desenvolvimento desse trabalho. Esperamos, dessa forma, estimular a produção de leituras e reflexões que contemplem a formação de educadores do campo. Nesse processo de construção histórica prevaleceu $\mathrm{o}$ respeito às diferenças e a valorização da identidade cultural dos povos camponeses, propondo uma educação inclusiva, questionadora e democrática, presente em diversas experiências de educação popular vinculadas à luta pela terra. Por fim, é importante registrar a defesa de políticas públicas que contribuam na formação de educadores para as escolas do campo brasileira. Sugiro aos leitores a continuidade desses estudos, com o objetivo de compreender a relevância de tais políticas no fortalecimento das relações com os movimentos sociais.

\section{Referências}

Abramovay, R. (1985). Nova forma de luta pela terra: acampar. Revista Reforma Agrária. 15.

Antunes, R. M. I.; Martins, M. F. A.; \& Martins, A. A. (Orgs). (2012). Territórios Educativos na Educação do Campo. Autêntica.

Begnami, J. B; Burghgrave, T. (2013). Pedagogia da Alternância e Sustentabilidade. Embrapa Editora.
Benjamin, C., \& Caldart, R. S. (2000). Projeto popular e escolas do campo. Brasília, DF: Articulação Nacional por uma Educação Básica do Campo.

Bezerra, N. L. (1999). Sem Terra aprende $e$ ensina: estudo sobre as práticas educativas do Movimento dos Trabalhadores Rurais. Campinas, SP: Autores Associados.

Bicalho, R. (2007). Alfabetização no MST: experiências com jovens e adultos na Baixada Fluminense. Campinas: Editora Komedi.

(2008). O projeto político pedagógico do movimento dos trabalhadores rurais sem terra: trajetórias de educadores e lideranças. Campinas: Editora Komedi.

Bogo, A. (2000). Reforma Agrária: Por um Brasil sem latifúndio! $4^{\circ}$ Congresso Nacional - MST.

Bogo, A. (Org.). (2002). MST: Caderno de cultura. (1). Gerações: coletâneas de poesias. São Paulo.

Caldart, R. S. (2000). Pedagogia do Movimento Sem Terra: escola é mais do que escola. Petrópolis, RJ: Vozes.

Caldart, R. S., Arroyo, M. G., \& Molina, M. C. (Orgs.). (2004). Por uma Educação do Campo. RJ: Vozes.

Caldart, R. S. (2010). Caminhos para a transformação da escola: Reflexões desde práticas da Licenciatura em Educação do Campo. Expressão Popular.

Caldart, R. S.; Stedile, M. E., \& Daros, D. (Orgs). (2015). Caminhos para transformação da Escola 2: Agricultura camponesa, educação politécnica e escolas do campo. Expressão Popular.

Caldart, R. S., \& Pereira, I. Brasil.; 
Alentejano, P., \& Frigotto, G. (Orgs). (2012). Dicionário da Educação do Campo. Expressão Popular.

Campos, M. (2015). Lutas dos movimentos sociais do campo e suas contradições na construção da educação do campo. RETTA - Revista de Educação Técnica e Tecnológica em Ciências Agrícolas. VIII (11).

De Rossi, V. L. S. (2004). Gestão do projeto político-pedagógico: entre corações e mentes. São Paulo: Moderna.

$$
\text { . (2003). Projetos político- }
$$

pedagógicos emancipadores: histórias ao contrário. Cadernos do Cedes, 23(61), 319-337.

. (2005). Mudança com

máscaras de inovação. Educação $e$ Sociedade, 26(61), 935-957.

Fernandes, B. M. (1999). MST: formação e territorialização em São Paulo. São Paulo: Hucitec.

Freire, P. (1997). Pedagogia da Autonomia: Saberes necessários à prática educativa. São Paulo: Paz e Terra.

(1975). Pedagogia do Oprimido. Rio de Janeiro: Paz e Terra.

(1983). Educação como prática de liberdade. Rio de Janeiro: Paz e Terra.

Gohn, M. da G. (2001). Movimentos Sociais e Educação. São Paulo: Ed. Cortez.

(2002). Teorias dos Movimentos Sociais. São Paulo: Loyola.

Gramsci, A. (1978). A Concepção Dialética da História; Os Intelectuais e a Organização da Cultura. São Paulo: Martins Fontes.
Hage, S. M. (2011). Por uma escola do campo de qualidade social: transgredindo o paradigma (multi)seriado de ensino. Em Aberto, 24(85), 97-113.

Honneth, A. (2003). Luta por reconhecimento: a gramática moral dos conflitos sociais. São Paulo: Ed. 34.

Molina, M. C. (2010). Educação do Campo e Pesquisa II. MDA/MEC.

Molina, M. C.; Freitas, H. C. de A. (Orgs). (2012). Em Aberto. INEP/MEC.

Molina, M. C. (Org.). (2014). Licenciaturas em Educação do Campo e o Ensino de Ciências Naturais: desafios à promoção do trabalho docente interdisciplinar. MDA/Série NEAD.

MST. (1999). Caderno de Educação n० 8 Princípios da Educação no MST. São Paulo.

MST. (2000). Caderno de Educação $\mathrm{n}^{\circ} 2$ (Alfabetização); $\mathrm{n}^{\circ} 3$ (Alfabetização de jovens e adultos: como organizar); $\mathrm{n}^{\circ} 4$ (Alfabetização de jovens $e$ adultos: didática da linguagem); $\mathrm{n}^{\circ} 5$ (Alfabetização de jovens e adultos: educação matemática); $\mathrm{n}^{\circ} 9$ (Como fazemos a Escola de Educação Fundamental). São Paulo.

MST. (2000). Caderno do educando: Pra soletrar a liberdade $n^{\circ}$ 1: Nossos Valores. São Paulo.

MST. (2001). Caderno do educando: Pra soletrar a liberdade $n^{\circ}$ 2: Somos Sem Terra. São Paulo.

MST. (2000). Cartilha de saúde $\mathrm{n}^{\circ} 5$. Construindo o conceito de saúde do MST. São Paulo.

Nosella, P. (1992). A Escola de Gramsci. Porto Alegre: Artes Médicas. 
Oliveira. L. M. T. (2015). Educação do campo e as lutas dos movimentos sociais pelos direitos às políticas públicas. RETTA - Revista de Educação Técnica e Tecnológica em Ciências Agrícolas. VIII(11).

Souza, M. A. (2012). Educação do Campo: propostas e práticas pedagógicas do MST. Petrópolis, RJ: Vozes.

Souza, M. A. (Org.). (2011). Práticas educativas do/no campo. Ponta Grossa: Editora UEPG.

Souza, M. A. (2010). Educação e Movimentos Sociais do Campo: a produção do conhecimento no período de 1987 a 2007. Curitiba: Ed. UFPR.

Stedile, J. P., \& Fernandes, B. M. (1999). Brava Gente: a trajetória do MST e a luta pela terra no Brasil. São Paulo: Editora Fundação Perseu Abramo.

Thompson, E. P. (1981). A miséria da teoria ou um planetário de erros: uma crítica ao pensamento de Althusser. Rio de Janeiro: Zahar Editores.

Tierra, P. (2002). Poesia. In: Bogo, A. (Org.) MST: Caderno de cultura, (1).

Veiga, I. P. A. (2004). Educação básica e Educação superior: Projeto políticopedagógico. Campinas, SP: Papirus.

Vendramini, C. R. (2000). Terra, trabalho e educação: experiências sócio-educativas em assentamentos do MST. Ijuí: Ed. UNIJUÍ.

Vendramini, C. R., \& Aued, B. W. (2009). Educação do Campo: desafios teóricos e práticos. Florianópolis: Editora Insular.

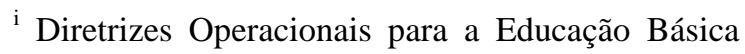
nas Escolas do Campo. (Parecer CNE/CEB $\mathrm{n}^{\circ}$ 36/2001 e Resolução CNE/CEB nº 01/2002).
}

\begin{abstract}
ii Programa de Apoio à Formação Superior em Licenciatura em Educação do Campo. Implantado pelo MEC - Ministério da Educação no ano de 2007, na Universidade Federal de Minas Gerais (UFMG), Universidade Federal da Bahia (UFBA), Universidade Federal de Sergipe (UFS) e Universidade Federal de Brasília (UnB).
\end{abstract}

iii DECRETO no 7.352, DE 4 DE NOVEMBRO DE 2010. Dispõe sobre a política de educação do campo e o Programa Nacional de Educação na Reforma Agrária - PRONERA.

iv Criado pelo Decreto $\mathrm{n}^{\mathrm{o}} 7.352$ e instituído por meio da Portaria ${ }^{\circ} 86$, de $1^{\circ}$ de fevereiro de 2013. Lançado pela presidente Dilma Rousseff, em março de 2012. Tem como propósito, oferecer apoio financeiro e técnico para viabilização de políticas públicas no campo.

v MST - Movimentos dos Trabalhadores Rurais Sem Terra; FETAG - Federação dos Trabalhadores na Agricultura; MPA - Movimento dos Pequenos Agricultores; MAB - Movimento dos Atingidos por Barragens; Quilombolas; Caiçaras; Ribeirinhos; Pescadores; Movimentos Indígenas, entre outros.

vi 1) Constituição da República Federativa do Brasil de 1988, Título 1, Artigo $3^{\circ}$ lV e Seção 1 - Da Educação, Artigo 206; 2) Lei de Diretrizes e Bases da Educação Nacional - LDB - no. 9.394/96, Artigos, 28, 78, 79; 3) ENERA - Encontro Nacional de Educadores da Reforma Agrária, 1997; 4) PRONERA - Programa Nacional de Educação na Reforma Agrária, 1998; 5) ProJovem Campo Saberes da Terra; 6) ProJovem Rural; 7) Resolução $\mathrm{n}^{\circ} 4$, de 13 de Julho de 2010, que define as Diretrizes Curriculares Nacionais Gerais para a Educação Básica e, nela, a educação do campo como modalidade de ensino; 8) Portaria $\mathrm{n}^{\circ} 391$, de 10 de maio de 2016. Estabelece orientações e diretrizes aos órgãos normativos dos sistemas de ensino para o processo de fechamento de escolas do campo, indígenas e quilombolas. 9) Nota Técnica Conjunta $\mathrm{N}^{\mathrm{o}} 3 / 2016$, que norteia a oferta das Licenciaturas em Educação do Campo de forma contínua e sustentável.

vii Licenciatura em educação do campo da UFRRJ. Áreas de conhecimento: Ciências Sociais e Humanidades.

viii O Programa Escola Ativa financiado pelo Ministério da Educação. Voltado para atender as escolas do campo com turmas multisseriadas.

${ }^{\text {ix }}$ Ver reportagem sobre fechamento das escolas do campo. Folha de São Paulo online, de 03/03/2014. 
x (http://agenciabrasil.ebc.com.br/educacao/noticia/2 014-03/sancionada-lei-que-dificulta-fechamentode-escolas-rurais-e-quilombolas, acessada em 2/08/2015).

Recebido em: 28/06/2016

Aprovado em: 21/07/2016

Publicado em: 03/08/2016

Como citar este artigo / How to cite this article / Como citar este artículo:

APA:

Santos, R. B. (2016). Interfaces entre escolas do campo e movimentos sociais no Brasil. Rev. Bras. Educ. Camp., 1(1), 26-46.

ABNT:

SANTOS, R. B. Interfaces entre escolas do campo e movimentos sociais no Brasil. Rev. Bras. Educ. Camp., Tocantinópolis, v. 1, n. 1, p. 26-46, 2016. 